\title{
Introduction. 'Seeing' Environmental Process in Time Questions of Evidence and Agency
}

\author{
David Sneath, University of Cambridge
}

\begin{abstract}
This introduction reviews the papers collected in this special section, papers that explore different visions of the environment and how they engender particular ways of seeing evidence of climatic and environmental change. A key aspect of such distinctive understandings seems to be the attribution of agency within conceptions of the environment that in each case are entangled with humans. Notions of anthropogenic and non-equilibrial environments are explored in several of the papers collected here, along with ongoing debates surrounding the concept of the Anthropocene. An awareness of climate change has brought new urgency to the project of grasping our entangled environments in the diversity of their human understandings.
\end{abstract}

Keywords: climate change, non-equilibrium environments, evidence, interdisciplinarity, agency, Anthropocene

The papers collected in this special section emerge from a network project entitled 'Climate Histories: Communicating Cultural Knowledge of Environmental Change'. Although organized by social anthropologists, this network was a multi-disciplinary enterprise and the aim was to pool expertise from a variety of disciplines, including social anthropology, archaeology, geography, history, literature and climate science to better understand accounts of the environment and its past. A previous publication from the network appeared as a forum piece on anthropology in public entitled 'Communicating Climate Knowledge: Proxies, Processes, Politics' (Diemberger et al. 2012). Here we focus on questions of how we perceive and understand the environment and how those visions contribute to ways of seeing evidence of change and the attribution of agency. 'The environment' took scientific shape, with various proxies in Europe, from the nineteenth century particularly, with 'climate' part of this. As Hastrup has noted:

It was only in the twentieth century that 'climate' moved out of geography and into physics and thus shifted from being directly observable and experiential to being an issue of atmospheric conditions, best grasped in large-scale models and statistics [Heymann 2010]. Gradually, this process has come full circle, once again grounding 
climate knowledge in solid earth and in social life, the Anthropocene having replaced the Holocene as the name of the present geological era. Technological and social advancement has come to a point where it is no longer possible to understand the Earth as independent of human influence, hence the Anthropocene [Ehlers and Krafft 2006]. (Hastrup 2012: 240)

In the first paper of this special section, Kirsten Hastrup addresses three different figurations of the Arctic environment: as poetry, as story and as science. In each of these, she argues, 'the ice becomes its own argument'. In their own ways, all of the papers in this collection touch upon one or more of these three registers for the apprehension of the environment, from the poetry of John Clare, to news stories of forest fires, to the climate science of the Intergovernmental Panel on Climate Change (IPCC). Each explores understandings of changing environments, past or present, and raises questions regarding the nature of evidence and agency.

Hastrup points out that the nineteenth-century exploration of the Arctic north created 'a bewildering natural space' in which it seemed impossible to get a proper picture of the land. 'The main obstacle was the ice, which although a solid form of water was as moveable and unpredictable as sea-waves'. The ice, she maintains, is an actor in the human/non-human network; it defies our account of it, being 'its own argument in complex ways. It was the repeated arguments of ice, then, that bewildered the early scientific explorers, generating places and spaces that moved or disappeared. Hastrup introduces the Inuit concept of sila, which can refer to both weather and climate, but is also understood as a sort of life, consciousness or mind. This reflects a poetics of the environment that at some point defies the language of signification, since words themselves are incapable of capturing its immensity.

When it comes to story, Hastrup shows how narratives reflect the 'elusiveness of place' in an environment that is in continuous motion. Here she draws upon Massey's (2005: 130) notion of places as integrations of time and space; as spatio-temporal events' Greenlandic place names are largely about features or activities indicating people's participation in the landscape, but they are increasingly inconsistent with a rapidly changing ice-scape. Stories of place, then, describe an environment that 'has now become so "fast" that it outruns the old terms'. But whatever the narrative, Hastrup shows how the ice remains central to the account, an inescapable and sometimes awesome presence, an agent in continuous activity as it shifts contour and spawns icebergs. The ice is also central to the environmental accounts of science, since much of the scientific interest in the region has been directed at comprehending the various arguments of the ice, and reading the information it contains. In the Arctic we see rather clearly how the various projects and languages of science are entangled with political interests - for much of the late twentieth century this reflected cold war military rivalry, since the superpowers sought to master this strategic but challenging terrain. Hastrup points out that the methods and languages of science never speak with a single voice, and the knowledge produced reflects the various concerns it was employed to address. This form of knowing the environment sits next to those of poetry and narrative, then, as partial accounts of something that ultimately escapes definitive description.

This approach is informed by Actor-Network Theory but seeks to move beyond it; simultaneously semiotic and material though it be, the ice-argument is not just another 
actant but a unifying theme in diverse accounts of the Arctic. Hastrup uses the concept of 'refrain' drawn from Deleuze and Guattari's notion of an aggregate that develops a particular territorial motif. "It is the refrain that "holds together" the heterogeneous elements of the territory' and gives a sense of consistency. In this sense the refrain of the Arctic is provided by the ice. It creates the physical environment, and provides the leitmotif of poetry, story and science'. Although the nature of agency and relationality may differ, in each of these registers we see evidence of accelerating climactic and environmental change: the accounts of Inuit hunters and ice scientists both speak of accelerating tempo in the argument of the ice.

Mike Hulme has observed that 'one of the reasons we disagree about climate change is because we believe different things about ourselves, the universe and our place in the universe' (Hulme 2009: xxxvi). In Joe Webster's paper, we are presented with a cosmology in which an increasingly turbulent environment is not understood within a narrative of climate change but in terms of eschatology, the knowledge of the portentous final events of history. For the millennialist Plymouth Brethren Christians of the Scottish fishing village of Gamrie described by Webster, events such as hurricanes, droughts and famines that are generally taken as evidence of climate change are actually evidence of the imminent earthly rule of the Devil and the 'end times' culminating in the Second Coming of Jesus Christ. Struggling to make a livelihood from fishing in an increasingly difficult EU regulatory context, the Aberdeenshire village has a population of around 700. In times that are seen as troubled, many have turned to evangelical Christianity, so that the village is now home to no fewer than six millennialist Protestant churches.

Here Webster describes a world in which climate change and millenarian Christianity are seen as rival eschatological accounts of salvation. Webster's informants find telling parallels between $\mathrm{Al}$ Gore's climate change rhetoric and their own millenarian visions of the 'end of days'. Of these narratives, however, one is profoundly false: the narrative of climate change entails the literally diabolical misrepresentation of evidence, causing millions to turn away from God and seek salvation in the works of Man. This ungodly ideology denies the omnipotence of God, promoting human pride and blinding the public to the signs of the end times. The very popularity of the climate change narrative is itself evidence of the waxing power of the Devil and the approaching millennium. Millenarian interpretations of this sort are also found in regions experiencing some of the most threatening consequences of climate change. In the thousand or more coral islands and islets of the Pacific Marshall Islands much of the land is less than a metre above sea level and the islanders have had to face the prospect that much or perhaps all of their territory may be lost to rising sea levels. Yet the sort of eschatological narratives described by Webster are also in wide circulation among millenarian Christians of the Marshall Islands (Rudiak-Gould 2009).

Webster presents views in which life is both modern and enchanted - 'made alive with a kind of magic'. In this enchanted plasticity, everyday life is connected, indivisible and full of cosmological meaning. While explicitly rejecting science, this enchantment emerges from a cosmology expressed in the distinctive religious register of narrative and poetic forms surrounding the Bible. It provides fundamentally different locations for both evidence and agency; for Webster's Plymouth Brethren the 'ultimate agentive force in a world of uncertainty' can only be God. 
As Laura Cameron reminds us here, we are said to be living in the Anthropocene, an epoch in which humans have come to be seen as a major geological agent affecting the environment of the planet. Dipesh Chakrabarty has argued that the growing scientific and public consensus regarding climate change means that the geologic now of the Anthropocene has become entangled with the now of human history' (Chakrabarty 2009: 212). This entanglement requires new sorts of intellectual work, in particular ones that dispense with the long-standing distinction between human and natural history, and that place global histories of capital in conversation with the species history of humans. Thinking in terms of humans as a species, he argues, is connected to the enterprise of 'deep history', that is, 'the history of humans that goes beyond these years of written records' and includes accounts of the genetic and cultural processes that created humanity over hundreds of thousands of years. 'Without such knowledge of the deep history of humanity', he notes, 'it would be difficult to arrive at a secular understanding of why climate change constitutes a crisis for humans' (ibid.: 213).

Archaeology offers a set of techniques and perspectives for the construction of such deep history, and Liliana Janik's paper describes how archaeological evidence reveals the changeability of environments in the past. Janik reviews studies of the south-eastern Baltic region from the sixth to the second millennium BCE, at a time when human populations are thought to have lived by fishing, hunting and gathering their food. The picture that emerges is one of continuous environmental change. Temperatures appear to have fluctuated throughout the period. Water levels rise and fall, lakes grow and shrink, ecosystems alter and the woods change in their composition. Furthermore, these changes do not neatly coincide but varied considerably from region to region and time to time. The study of bone assemblages gives us some idea of human activity over this period and reveals a number of surprising contrasts. Although there is no evidence to suggest that the same large mammals were not found throughout the region, very different patterns of consumption were found in different areas. Some assemblages show virtually no deer bones, for example, whereas in other places and periods they are very common. Similarly, the consumption of nuts seems to have varied from place to place and era to era. These differences seem relatively independent of the known environmental changes over that period, so that an environmental-deterministic account of adaptation becomes implausible. We are forced, Janik argues, to recognize the probability that the variations reflect cultural preferences that early populations had in interacting with their environment, choosing particular ways of hunting and consuming food among others, for reasons that we can now only speculate about. This is not an isolated case, Janik points out. Studies of comparable sites in Japan also suggest an environment in constant change and human populations with marked cultural differences in the ways they made use of their surroundings.

In this account, the environment is not only non-stable; the only stability is the metastability of variability. And although we can recognize the 'argument' of a nonequilibrial environment, it is also clear that the evidence of the human role in this environment might be said to be intensely cultural. We see evidence of human choice that is not a predictable reaction to environmental change conforming to the presumed logics of optimized survival, as in the standard environmental-determinist narrative of 'adaptation'. Deep history, then, is as intensely cultural as human history, to borrow 
Chakrabarty's terms. Here we see environmental variability matched by human variation, not in a relation of causal determination but rather in a looser dance in which both follow their own logics but remain fundamentally entangled. This mobile, nonequilibrial landscape challenges our notion of the fixity of landscape and of 'the natural' as a static given. Like Hastrup's Arctic, Janik's ancient Baltic is an agentive environment in the Latourian sense, moving to its own local rhythm rather than to the beat of some obvious global trend.

Laura Cameron observes that conceptual work that 'rematerializes human presence in nature' allows us to re-evaluate notions such as 'carrying capacity' - the idea of a maximum population of a biological species that any given environment can sustain indefinitely. Here we see a sort of convergence between social and environmental studies, since in both fields models of natural and social equilibria have been radically rethought. In social anthropology, the equilibrial assumptions of much classical structural-functionalist analysis have been widely critiqued since the 1970s. Environmental scientists have questioned ecological assumptions of equilibrium that have underpinned much neo-Malthusian thought about human relations with the environment. In his influential polemic 'Tragedy of the Commons', for example, Garret Hardin (1968) famously argued against common property on the grounds that the resource base is constantly under threat from behaviour that, at a disaggregated level, was logical. His thought-experiment was drawn from a pamphlet of 1833 advocating the enclosure of common land in England, and was used to propose, among other things, limiting the global population. Hardin contended that where many people graze their livestock on communal land it is in each individual's interest to keep adding to the number of their animals, even if the land is facing overgrazing and degradation. Hardin suggested that the way out of this destructive cycle was to introduce private ownership of land, or something formally like it, since by combining interest in both land and livestock an owner would have an interest in maintaining the potential of the land and preventing over-use. In the 1970s, this reasoning was applied to common land in African states such as Botswana, and policies were developed to divide and privatize public pastureland (Behnke and Scoones 1993). This reasoning was based upon the well-established concept of the 'carrying capacity' of land. ${ }^{1}$

Hardin's reasoning has been widely rejected by anthropologists and rangeland ecologists who found the model a poor guide to understanding the public-access grazing systems found in existing pastoral societies, in which land-use is generally limited by a variety of social and environmental constraints (e.g., Feemy et al. 1990; McCabe 1990). Ecological research has questioned the underlying assumption of the carrying capacity of land (Behnke and Scoones 1993). It has been argued that in areas with low and variable rainfall, available vegetation in a given place varies so much from year to year that yields cannot meaningfully be treated as variations around an equilibrial norm (Ellis et al. 1993). This 'disequilibrial' model of grazing systems suggests that carrying capacity for land might be a meaningless figure, and that the best management regime would not involve the exclusive use-rights of private property but would be one that allowed wide access to land to allow for mobility and opportunistic use of local resources. Concepts such as carrying capacity, then, like certain other 
Euro-American notions, appear to be of limited applicability in different parts of a complex world.

Laura Cameron engages directly in her paper with the notion of the Anthropocene. She points out that the notion of anthropogenic impact is far from new, dating back to the pioneering conceptual work on 'the environment' of Arthur Tansley (1871-1955), who also introduced the term 'ecosystem'. Cameron locates these innovations in a network of writings, thoughts and actions that centre not upon a person, but upon a place: Wicken Fen. This apparently unlikely source of wisdom is a patch of wetland some 15 kilometres north-east of Cambridge that was purchased by the U.K.'s National Trust in 1899 and became a site of scientific study. Located as it was near the local university and managed by a committee dominated by academics, Wicken Fen played a key role in the developing scientific understanding of the environment and the place of human action within it. The fen wetland was a distinctive ecosystem, including a rich diversity of plant and animal life, but it was a disappearing one. In the face of land drainage and the relentless extension of agricultural land, Wicken Fen had become an island, one of the few remnants of the great fenlands that used to stretch over much of East Anglia. But studies by Arthur Tansley, Harry Godwin (1901-1985), Max Walters (1920-2005) and others showed that this distinctive fenland ecosystem included and required human action, without which it would be colonized by different ecosystems. This example of 'anthropogenic nature' helped place humans firmly within the environment, suggesting that the natural was already to some extent anthropogenic wherever human populations had made a living by interacting with their surroundings. This position dissolved any remaining hard line between nature and culture and rejected a categorical distinction between modern and traditional anthropogenic processes.

In their recent introduction to a collection of papers in Cambridge Anthropology 30(2) devoted to the topic of naturalism, Candea and Alcayna-Stevens suggest that anthropologists might constructively 'take seriously the practices and beliefs which lie at the very heart of Western naturalism' (2012: 37). Cameron's work illuminates a small but by no means insignificant example of such practices, rooted as they are in place, and the beliefs they helped give rise to. Cameron points to the political significance of concepts of 'anthropogenic nature' in the face of powerful arguments presenting global warming as a natural process or of attempts to limit greenhouse gas emissions as an unjustifiable check on economic growth. In such views, human impacts are essentially insignificant, and must themselves answer to a presumed logic of human nature that will inevitably resist utopian projects of global management. This de-politicized nature is both beyond our control as simply an 'environment', and controlling of us through basic human drives. The notion of anthropogenic environment, however, leads us to something like a concept of political ecology, since questions of human values and responsibility become unavoidably present in descriptions of the 'natural' world. In emphasizing the political nature of the terms of ecological and environmental debates, Arturo Escobar has treated political ecology as the study of ecological distribution conflicts: 'Many communities in the world signify their natural environment, and then use it, in ways that markedly contrast with the more commonly accepted way of seeing nature as a resource external to humans and which humans can appropriate in any way they see fit' (Escobar 2006: 9). One need not go very far to find such contrasting views; 
this could be said of the conservationist and environmentalist perspectives that the ecologists of Wicken Fen helped to form.

In Cameron's paper, the fenland emerges as a resource of hope, a potential reservoir for the increasing amounts of groundwater in the region predicted by some models of climate change. But this is not an imagined pristine wilderness; rather, it is an entangled, agentive and cultural landscape. These resources of hope are, in Cameron's phrase, a 'human-produced, touched and lived nature'. And here Cameron is not referring only to the physical environment of the fen but also the conceptual resources to which it has given rise. She closes with Raymond Williams' call to recognize that 'there are ideas, and ways of thinking, with seeds of life in them' while others contain the seeds of a general death. Our future, he remarked, may well depend on making possible their common recognition.

What then of the conceptual resources that might be contained in the nature poetry of the extraordinary John Clare (1793-1864), whose work inspired Raymond Williams and who is now considered to be one of the most important nineteenth-century English poets? In their paper, Richard Irvine and Mina Gorji show us flickering visions of a less anthropocentric world, a genre of romantic environmentalism that finds beauty and value in weeds, wilderness and wild nature. In Clare's poetry we find a devotion to environments that do not conform to the human sensibilities of productivity or formal beauty but that are, like Hastrup's ice, simply their own arguments. Weeds, unkempt land and swamps are realms of beauty and nostalgic affection. Clare lived through, and was deeply embittered by, the enclosure of the commons in England, so roundly celebrated by Hardin's nineteenth-century pamphleteer. Clare's poetry is a powerfully moving lament for the ways of human and non-human life destroyed by the march of economic progress. Here we have a challenge to the Lockean logic of environment as resource. Animals and places appear with arguments of their own; we are made to see Clare's vision of the world as it must appear to Swordy Well heath and the swampliving snipe. Here we also get a closer look at the affective roots of conservationist, environmentalist and political ecology commitments: the impulse to attend to the living landscapes that are lost in the process of constructing our surroundings as resources, natural and human, and exploiting them. We are reminded that all intellectual endeavour is built upon affect and the impulse to make the arguments that generate forms of knowledge.

In her paper, Barbara Bodenhorn explores the construction of knowledge about a type of event that is so awesome that it simply imposes a certain amount of interpretive agreement. Like the collapsing iceberg described by Hastrup, the forest fire is a statement so powerful that in the first instance one simply has to flee from it. Yet people do contest the advance of the fire, trying to match its argument with firebreaks and devices of their own. Awesome Latourian agents though they may be, wildfires are entangled with people, since humans have long utilized fire to shape the landscape. The mutual entanglement is complex; in many areas it is dangerous to try and deny wildfire indefinitely and forest managers favour controlled burning. In others, such as the largely Zapotec-speaking district of Ixtlán in southern Mexico described by Bodenhorn, fire-fighting is a regular and highly communal activity. Most climate 
scientists see an increased frequency of forest fires as further evidence of increasing global temperatures and their destructive effects.

Bodenhorn's discussion raises questions regarding the shapes that information takes within forms of knowledge, what information is taken as evidence, and what an absence of information is evidence of. In the case of the forest fires that broke out in Russia in 2010 described by Anna Grigoryeva (2010), many fire-fighting activists found the absence of official information evidence of the failings of the state. Absence of evidence poses an interpretive dilemma, particularly in contexts where knowledge is contested: when should absence of evidence be treated as evidence of absence? Bodenhorn notes the Intergovernmental Panel on Climate Change (IPCC) felt bound to omit certain contributory factors in its predictions of sea level rise since, although there was agreement that these were operative, there was insufficient consensus on how to calculate them.

Finally, after poetry and narrative, we come to science. Here Charles Kennel's paper provides us with an insider's account of climate scientists' engagement with policy makers in the IPCC, the organization that has arguably had the greatest effect on international political responses to climate change. Established in 1988 by the World Meteorological Organization and the United Nations Environmental Programme, the IPCC is described by Hulme (2009: 96) as a hybrid or boundary organization between the worlds of science, public discourse and policy.

As a senior scientist with extensive experience of advising policy makers, Kennel describes the many questions posed by the process of advancing truth-claims on the basis of scientific authority. He sketches the processes used by the IPCC to try and generate a form of scientific consensus that is acceptable to national governments as a sound basis for action. Here again we have the opportunity to 'take science seriously, as Walford (2012: 104) puts it, by attending to both the institutional process that transforms data into knowledge and the political work done by such scientific practice. Kennel describes how the process of scientific assessment becomes a key site for the mediation of knowledge and power in which 'scientists and policy-makers compose, line by line, the statements pertinent to policy'. It is from an appreciation of the complexities of these processes that Kennel looks ahead to outline a vision of a rhizomic web of Knowledge Action Social Networks linking local communities to the international scientific one, and capable of carrying out the process of assessment at the local level, to transmit both the motivation for action to mitigate climate change and the knowledge needed to carry it out effectively.

Kennel's paper also provides a revealing insight into how the natural sciences might find value in the social sciences in general, and social anthropology in particular. In this vision, it is at the local level that much of the action suggested by this network would take place, and in the understandings of local societies, their concerns, perspectives and interests, that social anthropology would make a vital and distinctive contribution. As Crate and Nuttall, following Rosen (2007), note: 'The environment is only one of many actors in determining social change and plays a less important role than perceptions of nature' (Crate and Nuttall 2009: 20). The papers collected here represent a spectrum of such perceptions and explore the ways in which we might try to understand them. 


\section{Conclusion: Entangled Environments}

Several points emerge from these studies with particular clarity. The first concerns the location of humans and their agency within any environment. As Laura Cameron shows, the activities surrounding Wicken Fen helped to cement the notion that we already inhabit a profoundly anthropogenic environment, as well has helping to popularize the affective impulse to conserve it. But that is not to say that humans are the only or even the central agents. The location of agency is a second theme that emerges strongly. As Kirsten Hastrup so eloquently suggests, ice can be seen as the key agent and core refrain in the Arctic, and Liliana Janik's study indicates an ancient Baltic environment that may not have changed so rapidly but was nevertheless highly agentive, in the sense that it is better understood as non-equilibrial rather than stable. And this returns us to the notion of evidence. For agency is constructed and located as part of broader interpretive logics that we may think of as knowledge systems. In the millenarian Christian knowledge described by Webster, the environment we inhabit is categorically theocentric; agency, like evidence, must be correctly understood within the axiomatic truths revealed in the Word of God, not the works of man.

However, none of the visions of the environment described here is entirely anthropocentric; these environments appear as entangled with human agency rather than produced by it. We are never really alone in the wild; human statements are only some of the many that surround us. Whether it is the thunderous assertions of Hastrup's Arctic ice, or the quieter refrains of John Clare's bramble patches, we can perceive other arguments if we are attentive to them. Awareness of climate change has brought new urgency to the project of comprehending our entangled environments in the diversity of their human understandings. Forms of knowledge about the complex inter-linkages that include human activities within a deeply entangled environment are 'ecological' in Bodenhorn's terms, since they conceptualize systems of systems, and read selected information as evidence by proxy of wider systemic change. Such forms of knowledge are also cultural and the papers collected here give some sense of their diversity.

\section{Acknowledgements}

This collection emerged from an initiative launched in 2010 with Barbara Bodenhorn and Hildegard Diemberger as a result of an AHRC Network grant: 'Climate Histories: Communicating Cultural Knowledge of Environmental Change.' It would not have been possible without the hard work and enthusiasm of many people, only some of whom I am able to mention here. Firstly I would like to thank Richard Irvine, who has been central to the creative and editorial process throughout. The entire network owes an enormous debt of gratitude to Libby Peachey, who has sustained the initiative and provided superb administrative support. I would like to thank Jonas Tinius for his energetic assistance and the Centre for Research in the Arts, Social Sciences and Humanities (CRASSH), University of Cambridge, for hosting the associated conference 'Climate Histories: Communicating Cultural Knowledge of Environmental Change', 21-22 January 2011. 


\section{Note}

1. As Tim Ingold points out, the theory that underpinned this notion represented the relationship between livestock and land as a parallel with the 1920s Lotka-Volterra model by which 'two species, one of which feeds on the other, must undergo perpetual and undamped oscillations in numbers. The predators usually increase to a point of overloading their food supply, then decline again through malnutrition, giving the prey a chance to increase, consequently allowing the predator to increase, causing the prey to decline and so on' (1980: 38). Since that time, there has been an increasing awareness of the shortcomings of this model.

\section{References}

Behnke, R., and I. Scoones. 1993. Rethinking Range Ecology: Implications for Rangeland Management in Africa. In Range Ecology at Disequilibrium: New Models of Natural Variability and Pastoral Adaptation in African Savannahs (eds.) R. Behnke, I. Scoones and C. Kerven, 1-30. London: ODI, IIED and Commonwealth Secretariat.

Candea, M., and L. Alcayna-Stevens. 2012. Internal Others: Ethnographies of Naturalism. Cambridge Anthropology 30, no. 2: 36-47.

Chakrabarty, D. 2009. The Climate of History: Four Theses. Critical Inquiry 35, no. 2: 197-222.

Crate, S., and M. Nuttall. 2009. Introduction: Anthropology and Climate Change. In Anthropology and Climate Change: From Encounters to Actions (eds.) S. Crate and M. Nuttall, 9-36. Walnut Creek, CA: Left Coast Press.

Diemberger, H., K. Hastrup, S. Schaffer, C.F. Kennel, D. Sneath, M. Bravo, H.-F. Graf, J. Hobbs, J. Davis, M.L. Nodari, G. Vassena, R. Irvine, C. Evans, M. Strathern, M. Hulme, G. Kaser and B. Bodenhorn. 2012. Communicating Climate Knowledge: Proxies, Processes, Politics. Current Anthropology 53, no. 2: 226-244.

Ehlers, E., and T. Krafft (eds.). 2006. Earth Systems Science in the Anthropocene. New York: Springer.

Ellis, J., M. Coughenour and D. Swift. 1993. Climate Variability, Ecosystem Stability, and the Implications for Range and Livestock Development. In Range Ecology at Disequilibrium: New Models of Natural Variability and Pastoral Adaptation in African Savannahs (eds.) R. Behnke, I. Scoones and C. Kerven, 31-41. London: ODI, IIED and Commonwealth Secretariat.

Escobar, A. 2006. Difference and Conflict in the Struggle over Natural Resources: A Political Ecology Framework. Development 49, no. 3: 6-13.

Feemy, D., B. Fikret, B. McCay and J. Acheson. 1990. The Tragedy of the Commons: Twentytwo Years Later. Human Ecology 18, no. 1: 1-19.

Grigoryeva, A. 2010. Chasing Wildfires: The Temporality of a News Event. MPhil diss., Department of Social Anthropology, Cambridge University.

Hardin, G. 1968. The Tragedy of the Commons. Science 162: 1243-1248.

Hastrup, K. 2012. Response to 'Communicating Climate Knowledge: Proxies, Politics, Process'. Current Anthropology 53, no. 2: 240-241.

Heymann, M. 2010. The Evolution of Climate Ideas and Knowledge. WIREs Climate Change 1, no. 4: 581-597.

Hulme, M. 2009. Why We Disagree about Climate Change: Understanding Controversy, Inaction and Opportunity. Cambridge: Cambridge University Press.

Ingold, T. 1980. Hunters, Pastoralists, and Ranchers: Reindeer Economies and Their Transformations. Cambridge: Cambridge University Press.

Massey, D. 2005. For Space. London: Sage. 
McCabe, T. 1990. Turkana Pastoralism: A Case Against the Tragedy of the Commons. Human Ecology 18, no. 1: 81-103.

Rosen, A.M. 2007. Civilizing Climate: Social Responses to Climate Change in the Ancient Near East. Walnut Creek, CA: AltaMira.

Rudiak-Gould, P. 2009. The Fallen Palm: Climate Change and Culture Change in the Marshall Islands. Saarbrucken: VDM Verlag.

Walford, A. 2012. Data Moves: Taking Amazonian Climate Science Seriously. Cambridge Anthropology 30, no. 2: 101-117.

David Sneath is Reader in the Anthropology of Political Economy at the University of Cambridge. He was the Principal Investigator of the AHRC-funded Network project 'Climate Histories: Communicating Cultural Knowledge of Environmental Change'. 